\title{
EXPERIMENTAL AND FINITE DIFFERENCE MODELLING OF BOREHOLE MACH WAVES
}

\author{
by \\ N.Y. Cheng, Zhenya Zhu, C.H. Cheng, and M.N. Toksöz \\ Earth Resources Laboratory \\ Department of Earth, Atmospheric, and Planetary Sciences \\ Massachusetts Institute of Technology \\ Cambridge, MA 02139
}

\begin{abstract}
A series of model experiments are done in the ultrasonic laboratory to study the radiation of downhole sources in a variety of formations. Three models are used in the experiments. They are a lucite model, a lucite model with free glass pipe in the center, and a glass cased soil model. In addition, the finite difference modelling technique is used to simulate the wave propagation in these models and the results of the laboratory and numerical experiments are compared. In the lucite borehole model the waveforms recorded in the experiment agree very well with the finite difference synthetics. The snapshots of the wavefield from finite difference simulation show the radiation pattern of the $\mathrm{P}$ and $\mathrm{S}$ wave in the lucite formation. These patterns are consistent with the theoretical calculations. In the lucite model with the free glass pipe, the finite difference synthetics are also in good agreement with the experimental observations, especially for the conical P-wave arrival. The angle between the wavefront of the conical $\mathrm{P}$ wave and the borehole axis observed from the snapshot agrees with the theory. In the cased soil model the arrival time of the finite difference synthetics is in good agreement with the lab measurements. The relative amplitudes of the $\mathrm{P}$ wave and Mach wave are not correctly modelled because of no intrinsic attenuation in the finite difference calculation. The Mach cone angle from the snapshot agrees with the theoretical prediction. Finally the finite difference method is used to simulate the Mach wave propagation in the formation with two horizontal layers. In the two slow formation layers case, Mach wave generated in the first layer reflected back from and transmitted through the boundary and another Mach wave is generated at the second layer when the Stoneley wave travels into the second layer. In the one slow and the one fast formation layer case, the Mach wave generated in the slow formation is reflected back at the boundary and leaked into the fast formation layer. There is no Mach wave in the fast formation layer.
\end{abstract}




\section{INTRODUCTION}

Wave propagation in a fluid-filled borehole has been studied intensively over the last decade. Most of these works are focused on the wavefield measured inside the borehole. They concern the propagation problem with the source and the receiver inside the borehole and how the formation parameters are related to the microseismograms (full waveform acoustic logging). In recent years there has been a growing interest in the wavefield outside of the borehole. It is crucial to the design of downhole seismic sources, which are important in the cross hole and reverse vertical seismic profile surveys. This leads to the interest in a new type of wave: Borehole Mach wave in the slow formation, which has been confirmed by a field data set as well as by numerical modelling (de Bruin and Huizer, 1989; Meredith, 1990; Ben-Menahem, 1991). The borehole Mach wave is similar to the Mach wave in the aerodynamic case, in which it is generated by an airplane traveling at a speed faster than the speed of sound. In the borehole case when Stoneley wave velocity is greater than the formation shear wave velocity, the Stoneley wave radiates its energy into the formation as shear wave constructively to form conical wavefront. You can also view this as a source moving along the borehole with Stoneley velocity and radiate shear wave into the formation.

In this paper we use the finite difference method to model wave propagation in the borehole geometry. The borehole Mach wave has been observed in the field experiments, but has not been studied in the ultrasonic laboratory. So a series of experiments to observe the wavefield outside of the borehole model are done in the ultrasonic lab. These lab measurements are compared with the finite difference synthetics. The snapshot of finite difference simulation gives a whole picture of the wavefield inside and outside of the borehole. Mach wave propagation in a horizontally layered formation is also investigated.

\section{FINITE DIFFERENCE METHOD}

In this section we outline the finite difference method in cylindrical coordinate. To test this method the results obtained from finite difference calculations are compared with the ones from the discrete wavenumber method, which are known to be analytically accurate.

The finite difference method was applied to the acoustic logging problem by Stephen et al. (1985). They used the second order displacement formula of wave equation and consider boundary condition at the borehole wall explicitly. A better way to do this is to discretize the first order velocity-stress formulation of the wave equation on a staggered grid (Virieux 1986; Kostek 1991). This second approach is used in this paper. 
We consider a cylindrical fluid-filled borehole embedded in an isotropic elastic formation (Figure 1). Under azimuthal symmetry (wavefield independent of $\theta$ ), the elastic wave equation in their cylindrical coordinate components form can be written as:

$$
\begin{gathered}
\rho \frac{\partial v_{r}}{\partial t}=\frac{1}{r} \frac{\partial\left(r \tau_{r r}\right)}{\partial r}-\frac{\tau_{\theta \theta}}{r}+\frac{\partial \tau_{r z}}{\partial z} \\
\rho \frac{\partial v_{z}}{\partial t}=\frac{1}{r} \frac{\partial\left(r \tau_{r z}\right)}{\partial r}+\frac{\partial \tau_{z z}}{\partial z}
\end{gathered}
$$

where $\left(v_{r}, v_{z}\right)$ is the displacement vector and $\left(\tau_{r r}, \tau_{0 \theta}, \tau_{z z}, \tau_{r z}\right)$ is the stress tensor. $\rho$ is the density. Taking the time derivative on both sides of the strain-stress relations, they become:

$$
\begin{gathered}
\frac{\partial \tau_{r r}}{\partial t}=\lambda\left(\frac{1}{r} \frac{\partial\left(r v_{r}\right)}{\partial r}+\frac{\partial v_{z}}{\partial z}\right)+2 \mu \frac{\partial v_{r}}{\partial r} \\
\frac{\partial \tau_{\theta \theta}}{\partial t}=\lambda\left(\frac{1}{r} \frac{\partial\left(r v_{r}\right)}{\partial r}+\frac{\partial v_{z}}{\partial z}\right)+2 \mu \frac{\partial v_{r}}{\partial r} \\
\frac{\partial \tau_{z z}}{\partial t}=\lambda\left(\frac{1}{r} \frac{\partial\left(r v_{r}\right)}{\partial r}+\frac{\partial v_{z}}{\partial z}\right)+2 \mu \frac{\partial v_{z}}{\partial z} \\
\frac{\partial \tau_{r z}}{\partial t}=\mu\left(\frac{\partial v_{r}}{\partial z}+\frac{\partial v_{z}}{\partial r}\right)
\end{gathered}
$$

where $\lambda$ and $\mu$ are Lamé constants. Equation (1) - (6) are the wave equation in the form of first-order partial differential equations. This set of equations can be discretized on a staggered grid with centered finite differences (Figure 2). One advantage of this discretization is that we don't need to treat the fluid-solid boundary explicitly (Virieux 1986). This provides us an easy way to simulate the wave propagation in a fluid-filled borehole surrounded by an elastic formation.

To minimize the size of the computational grid, we choose the $r$ and $z$ axes as symmetry axes. A point compressional source is applied at the origin. Damping layers are used at the bottom and left boundary of the grid to absorb the incident waves. The stable condition of this finite difference scheme is given by:

$$
V_{P} \Delta t \sqrt{\frac{1}{\Delta x^{2}}+\frac{1}{\Delta z^{2}}}<1
$$


where $\Delta t$ is the grid time step, $\Delta r$ and $\Delta z$ are the grid step in the direction of the $r$-axis and $z$-axis, respectively. $V_{p}$ is the maximum $\mathrm{P}$-wave velocity on the grid. In order to minimize the grid dispersion the grid size is chosen by:

$$
\min (\Delta r, \Delta z)<\frac{\lambda_{\min }}{10}
$$

where $\lambda_{\min }$ is the minimum wavelength in the problem.

To test the results of the finite difference method, we compare them with the results obtained by the discrete wavenumber method (Cheng and Toksöz, 1981). The model used in the test is a $10-\mathrm{cm}$ radius fluid-filled borehole surrounded by an elastic formation, whose parameters are listed in Table 1. The compressional wave velocity and density of the fluid are $1.8 \mathrm{~km} / \mathrm{s}$ and $1.0 \mathrm{~g} / \mathrm{cc}$, respectively. The source-receiver separation is $2.0 \mathrm{~m}$ and they are located at the center of the borehole. A Kelly source is applied at the origin of the grid with a center frequency of $10 \mathrm{kHz}$ (Stephen et al., 1985). A $256 \times 512$ grid was used in the computation with $\Delta r=\Delta z=5 \mathrm{~mm}$. The time step is $\Delta t=5.0 \times 10^{-7} \mathrm{~s}$. A 50 grid point sponge layer is used as the absorbing boundary. This finite difference code is implemented on ERL's nCUBE parallel computer with a grid decomposition algorithm. This algorithm decomposes the whole grid into subgrids and then maps these subgrids into the nodes. The finite difference algorithm is calculated on each subgrid. Subgrid boundary values are communicated between nearby nodes.

Figure 3 shows the comparison of the full waveform obtained by the finite difference method and the discrete wavenumber method. They are in very good agreement. The grid dispersion is well suppressed. The body waves ( $\mathrm{P}$ and $\mathrm{S}$ wave) and the surface waves (Stoneley and pseudo-Rayleigh) are correctly modelled by the finite difference method. In the finite difference calculation some small boundary reflections can be seen at the end of the microseismogram.

\section{ULTRASONIC EXPERIMENTS AND FINITE DIFFERENCE SYNTHETICS}

Acquisition of data from scaled borehole models is conducted in the ultrasonic laboratory. The measurement of the wavefield outside of the borehole is not an easy thing to do in the field, but it is very easy from the scaled borehole model in the laboratory. A hydrophone is used as the source which is centered inside the borehole. This compressional wave source is triggered by a function generator at $8 \mathrm{~Hz}$ repeat rate. The receiver is a transducer mounted on the outside wall of the borehole model. The receiver measures the stress in the radial direction. The output signal from the receiver passes through a preamplifier and a bandpass filter. Then it is digitized and stored in an IBM/AT computer. The whole model is located inside a water tank. Figure 4 shows 
the detail of the experimental setup. During the experiment the receiver position is fixed. The source is moved by step motor to collect different offset seismograms.

\section{Lucite Borehole Model}

In the first experiment a cylindrical block of lucite $15 \mathrm{~cm}$ in diameter and $30 \mathrm{~cm}$ in height is used as the model. Physical parameters of lucite are listed in Table 1. A hole of $1.48 \mathrm{~cm}$ in diameter is drilled at the center of the cylinder. The receiver is located at the outside of the cylinder and $5 \mathrm{~cm}$ away from the bottom. The source started at the same level as the receiver and then moved up with an increment of $0.5 \mathrm{~cm}$ after each measurement. There are a total of 40 traces recorded in the experiment. The waveforms are plotted in Figure 5. In the plot each trace is normalized by its own maximum. The $\mathrm{P}$ - and S-wave arrivals are shown clearly in the plot. There are some reflections from the edges of the model in the seismograms.

A ten times larger model is used to do the finite difference simulation. A Kelly source with a center frequency of $10 \mathrm{kHz}$ is used as the source. The fluid velocity is set at $1.5 \mathrm{~km} / \mathrm{s}$. Other parameters are the same as used in the previous section. The finite difference synthetics are plotted in Figure 6 with the same source-receiver geometry as in the experiment. Also the normalization is by each trace's own maximum. The time scale in the finite difference synthetics is ten times larger than the one in the experiment plot. The finite difference synthetics are matched very well with the waveforms recorded in the experiment.

Figure 7 shows the snapshot of wavefield $\tau_{r r}$ at $\mathrm{t}=0.5 \mathrm{~ms}$. The radiation pattern of the $\mathrm{P}$ wave and the $\mathrm{S}$ wave can be observed from this snapshot. $\mathrm{P}$-wave amplitude reaches a maximum value in the horizontal direction and a minimum value in the vertical direction. S-wave amplitude gets the maximum value around an angle of 45 degrees from the horizontal direction and approaches the minimum in the vertical and horizontal directions. This is only one quarter of the whole radiation pattern. Using the symmetry conditions it is not difficult to imagine the complete picture. This radiation pattern is consistent with the theoretical radiation pattern calculations (Meredith, 1990). One of the boundary conditions at the borehole wall is the continuity of radial stress. This also can be seen clearly from the snapshot.

\section{Lucite Borehole Model With Free Glass Pipe}

The second experiment is done using the same lucite borehole model except a free glass pipe is put inside the borehole. The dimension of the glass pipe is $0.95 \mathrm{~cm}$ inner diameter and $1.2 \mathrm{~cm}$ outer diameter. The physical parameters of glass are given in Table 1. The 40 traces are collected in the experiment with the same settings as in the 
previous one. Measured waveforms are plotted in Figure 8. Comparing Figure 8 with Figure 5, there is an arrival before the $\mathrm{P}$ wave in Figure 8 . This early arrival is the conical $\mathrm{P}$ wave. The finite difference synthetics and snapshot are given in Figure 9 and 10 , respectively. Once again the finite difference synthetics are in very good agreement with the laboratory measurements.

The conical $\mathrm{P}$ wave is generated by the wave which propagates in the glass with glass $\mathrm{P}$-wave velocity and radiates energy into the formation which travels with the formation $\mathrm{P}$-wave velocity. Because the lucite $\mathrm{P}$-wave velocity is slower than the glass $\mathrm{P}$ wave velocity, this radiation is added constructively to form a plane wavefront (Figure 10). The actual shape of this wavefront is a cone because of the azimuthal symmetry. The wavefront intercepts the borehole wall with an angle $\phi$, which can be approximately calculated by the following equation:

$$
\phi=\sin ^{-1}\left(\frac{V_{\text {lucite }}}{V_{\text {glass }}}\right)
$$

where $V$ is the $\mathrm{P}$-wave velocity. We say it is approximate because there is a thin layer of fluid between the glass and the lucite. In our experimental case $\phi$ is about 29 degrees. This angle agrees with what we see from the snapshot. Finally the radiation patterns of the $\mathrm{P}$ and $\mathrm{S}$ waves are slightly changed from the lucite borehole case. This shows the free glass pipe effect on the radiation pattern.

\section{Glass Cased Soil Borehole Model}

In the previous two experiments the formation shear wave velocities are faster than the Stoneley wave velocity, so they cannot generate the Mach wave from the Stoneley wave. Therefore in this experment we chose low velocity soil as the borehole model with a glass pipe casing. The glass casing increases the Stoneley wave velocity. The outer diameter of the soil cylinder is $6.6 \mathrm{~cm}$. The height of the soil cylinder is $48 \mathrm{~cm}$. The inner diameter of the casing is $0.95 \mathrm{~cm}$ and the outer diameter of the casing is $1.2 \mathrm{~cm}$. Waveforms of 25 traces measured in the experiment are plotted in Figure 11. A source with a center frequency of $30 \mathrm{kHz}$ is used in this experiment. The source step in the vertical direction is $0.65 \mathrm{~cm}$. Figure 11 shows the $\mathrm{P}$-wave arrival followed by a shear wave (or Mach wave) arrival. The Mach wave arrival is generated by the Stoneley wave which travels vertically along the borehole and radiates energy into the formation as shear waves (de Bruin and Huizer, 1989). The finite difference synthetics are shown in Figure 12. The finite difference synthetics and the laboratory measurements are in reasonable agreement. The arrival time of the $\mathrm{P}$ wave and Mach wave are correctly predicted by the synthetics. Figure 12 also shows the increase of the Mach-wave amplitude relative to the $\mathrm{P}$-wave amplitude. The relative amplitude of the $\mathrm{P}$ and $\mathrm{Mach}$ wave are not 
modelled correctly by the finite difference method. The reason is that the soil is a low $\mathrm{Q}$ material. The $\mathrm{P}$ wave mostly travels in the soil, with decreased amplitude due to the intrinsic attenuation. On the other hand the Mach wave travels inside the borehole as a Stoneley wave, which is guided by the glass casing. The Stoneley wave suffers little attenuation. Then it travels to the receiver as a shear wave with a short path inside the soil. So in the lab measurements the amplitude of the Mach wave is larger than the $\mathrm{P}$-wave amplitude. In our finite difference calculation there is no attenuation included.

The snapshot of the wavefield at time $1.15 \mathrm{~ms}$ is given in Figure 13. There is a very strong Stoneley wave inside the borehole because of the casing. The snapshot clearly shows the Mach wave with a straight wavefront (or Mach cone). The angle between the wavefront and the borehole axis is determined by:

$$
\alpha=\sin ^{-1}\left(\frac{V_{s}}{V_{s t}}\right)
$$

where $V_{s}$ is the formation shear wave velocity and $V_{s t}$ the Stoneley wave velocity. The Stoneley wave velocity at the low frequency limit in a cased borehole is given by (White, 1965; Marzetta and Schoenberg, 1985):

$$
V_{s t}=\frac{V_{f}}{\sqrt{1+\frac{\rho_{f} V_{f}^{2}}{M}}}
$$

where $V_{f}$ is the fluid velocity and $\rho_{f}$ the fluid density. $M$ is given by:

$$
M=\mu_{c} \frac{\mu+\left(\mu_{c}-\mu\right)\left(1-\frac{\alpha_{c}^{2}}{\beta_{c}^{2}}\right)\left(1-\frac{r_{a}^{2}}{r_{b}^{2}}\right)}{\mu_{c}-\left(\mu_{c}-\mu\right) \frac{\alpha_{c}^{2}}{\beta_{c}^{2}}\left(1-\frac{r_{a}^{2}}{r_{b}^{2}}\right)}
$$

where $r_{a}$ and $r_{b}$ are the inner and the outer radius of the casing. The subscript $c$ refers to casing velocities and shear moduli. $\mu$ is the shear moduli of the formation. In the glass cased soil model we substitute those parameters into the equation (11) and (12) and obtain the low frequency Stoneley velocity about $1290 \mathrm{~m} / \mathrm{s}$. The calculated angle $\alpha$ is about 8 degrees. This angle is almost the same as we observed from the snapshot.

\section{MACH WAVE IN HORIZONTAL LAYERED FORMATION}

In this section the finite difference method is used to simulate Mach wave propagation in a formation with horizontal layers. 
The model used in the investigation is a steel cased borehole surrounded by a formation with two horizontal layers (Figure 14). They are labeled as layer 1 and layer 2. The plot also shows the receiver array. First we consider two slow formation layers. The parameters of these layers are listed in Table 1. Figures 15 and 16 show the synthetic waveforms in the formation and the snapshot of the wavefield. The Mach wave generated in layer 1 travels downward. It hits the layer boundary and some of its energy reflects back to layer 1 and some of its energy transmits into layer 2 . Because layer 2 is a slow formation and the condition to generate the Mach wave is still valid, the borehole Stoneley wave in layer 2 generates another Mach wave. It is not very easy to understand the arrivals before the transmitted Mach wave from the seismograms (Figure 15). But it becomes very clear from the snapshot of the wavefield that these arrivals are the second Mach wave (Figure 16).

Then we consider one slow formation layer and one fast formation layer. The layer 2 is changed to a fast formation, whose parameters are the same as the test model listed in Table 1. Figures 17 and 18 are the plots of the synthetic seismograms and the wavefield snapshot. In this case the Mach wave is reflected back to the slow formation. Some of its energy penetrated into the fast formation but the wavefront is not a plane any more. The reason is the following: in the slow formation of layer 1 the velocity of the Stoneley wave is about $1200 \mathrm{~m} / \mathrm{s}$ and the shear wave velocity is $600 \mathrm{~m} / \mathrm{s}$. So the Mach cone angle is 30 degrees; the incident angle of the Mach wave upon the layer boundary is 60 degrees. The critical angle for the shear wave from the slow formation to the fast formation is about 15 degrees. The Mach wave is a post-critical incident wave. That is why there is no transmitted plane wave in the fast formation. When the Stoneley wave travels down to the fast formation, the condition to form the plane shear wave does not hold so there is no Mach wave in the fast formation.

\section{CONCLUSION}

Ultrasonic experiments are conducted on the three borehole model. They are a lucite model, a lucite model with free glass pipe and a glass cased soil model. The measured seismograms in the experiments agree with the finite difference synthetics. In these experiments we not only observed the formation $\mathrm{P}$ - and $\mathrm{S}$-wave arrivals but also the conical $\mathrm{P}$ wave in the free glass pipe situation and the Mach wave in the cased soil situation. All these arrivals are also seen in the synthetics. The snapshots of finite difference simulation show the radiation pattern of the $P$ and $S$ wave in the formation and the plane wavefronts of the conical $P$ wave and Mach wave. The angles between the wavefronts of the conical $\mathrm{P}$ and Mach wave with the borehole axis in the snapshots are consistent with the theoretical predictions. The finite difference method is also used to study Mach wave reflection and transmission at a horizontal layer boundary. 


\section{ACKNOWLEDGEMENTS}

We would like to thank Ted Charrette of nCUBE for helping us to parallelize the finite difference code on the nCUBE, and Denis Schmitt of Mobil for assistance in using his discrete wavenumber program. This work was supported by the Borehole Acoustics and Logging Consortium at M.I.T. Part of the computing was done at the ERL/nCUBE Geophysical Center for Parallel Processing.

Table 1: Model Physical Parameters

\begin{tabular}{|l|l|l|l|}
\hline & $V_{p}(\mathrm{~m} / \mathrm{s})$ & $V_{s}(\mathrm{~m} / \mathrm{s})$ & $\rho(\mathrm{g} / \mathrm{cc})$ \\
\hline Test Model & 4000 & 2300 & 2.3 \\
\hline Lucite & 2700 & 1300 & 1.8 \\
\hline Glass & 5500 & 3400 & 2.65 \\
\hline Soil & 1670 & 170 & 1.29 \\
\hline Steel & 6100 & 3350 & 7.5 \\
\hline Layer 1 & 1800 & 600 & 2.3 \\
\hline Layer 2 & 1800 & 300 & 2.3 \\
\hline
\end{tabular}




\section{REFERENCES}

Ben-Menahem, A., 1990, Signal enhancement with Mach-Cerenkov waves; J. Acoust. Soc. Am. 90, 500-506.

Cheng, C.H., and M.N. Toksöz, 1981, Elastic wave propagation in a fluid-filled borehole and synthetic acoustic logs; Geophysics, 46, 1042-1053.

de Bruin, J., and W. Huizer, 1989. Radiation from waves in boreholes, Scientific Drilling, $13-10$.

Kostek, S., 1990, Modelling of elastic wave propagation in a fluid-filled borehole excited by a piezoelectric transducer; M.S. Thesis, Massachusetts Institute of Technology, Cambridge, Mass.

Marzetta, T., and M. Schoenberg, 1985, Tube wave in cased boreholes; SEG Annual Meeting Abstracts.

Meredith, J.A., 1990, Numerical and analytical modelling of downhole seismic source: the near and far field; Ph.D. Thesis, Massachusetts Institute of Technology, Cambridge, Mass.

Stephen, R.A., F. Pardo-Casas, and C.H. Cheng, 1985, Finite-difference synthetic acoustic logs; Geophysics, 50,1588-1609.

Virieux, J., 1986, P-SV wave propagation in heterogenous media: velocity-stress finite difference method; Geophysics, 51,889-901.

White, J., 1965, Seismic waves, radiation, transmission and attenuation; McGraw-Hill. 


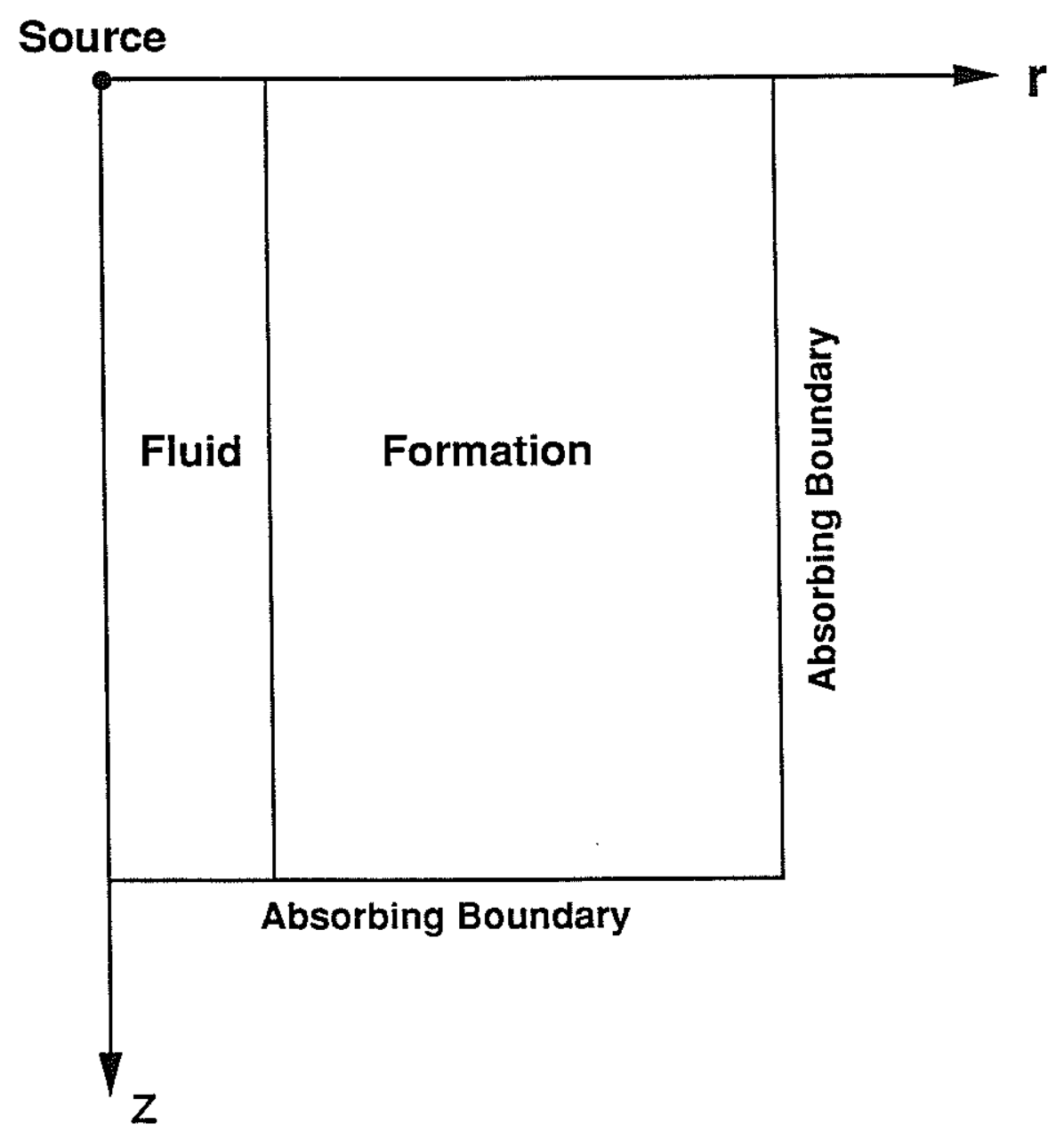

Figure 1: Borehole geometry used for the finite difference simulation. A source is located at the origin. The $r$-axis and $z$-axis are also the symmetry axes. 

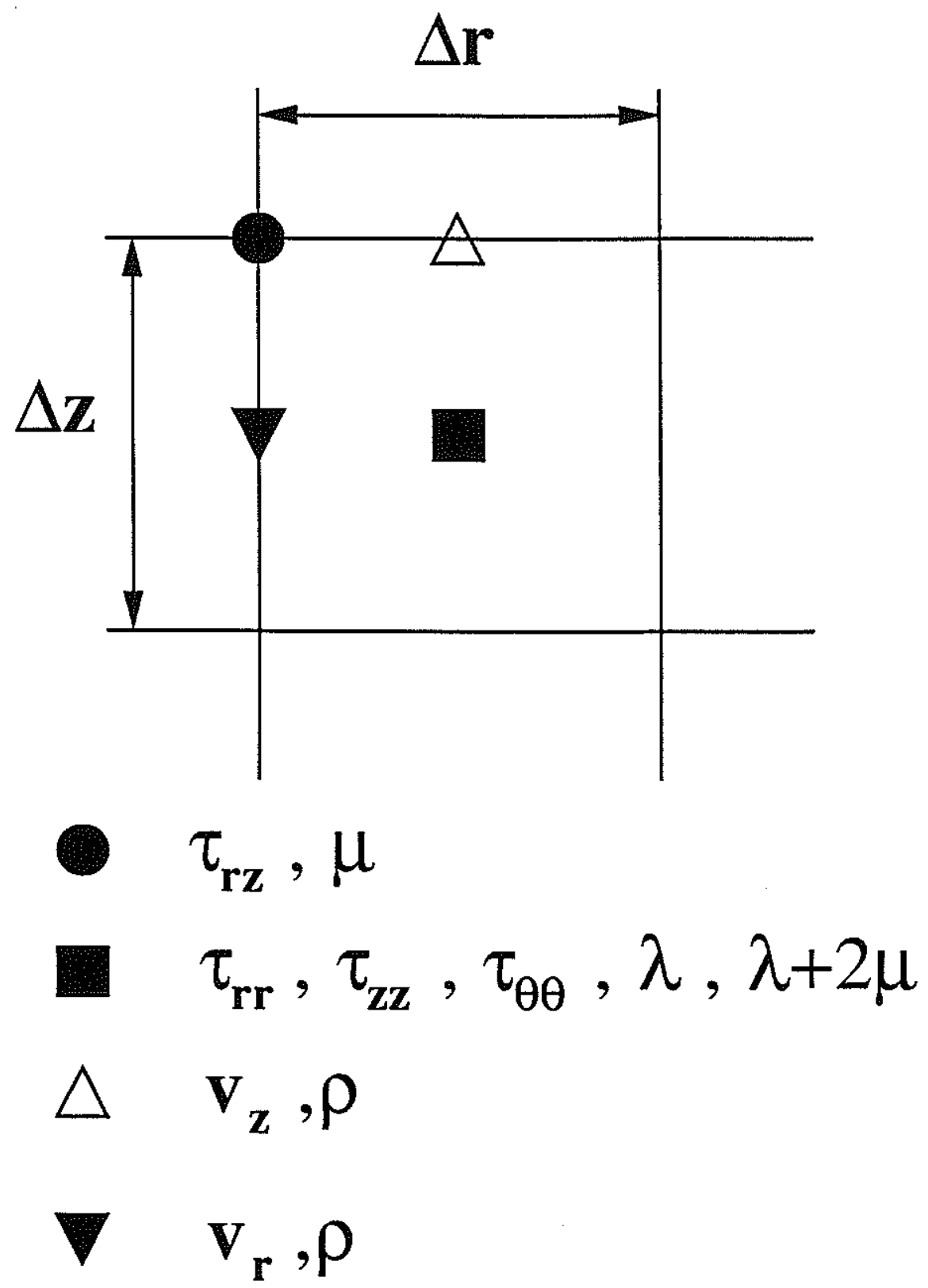

Figure 2: Discretization of the first order hyperbolic equations on a staggered grid. 


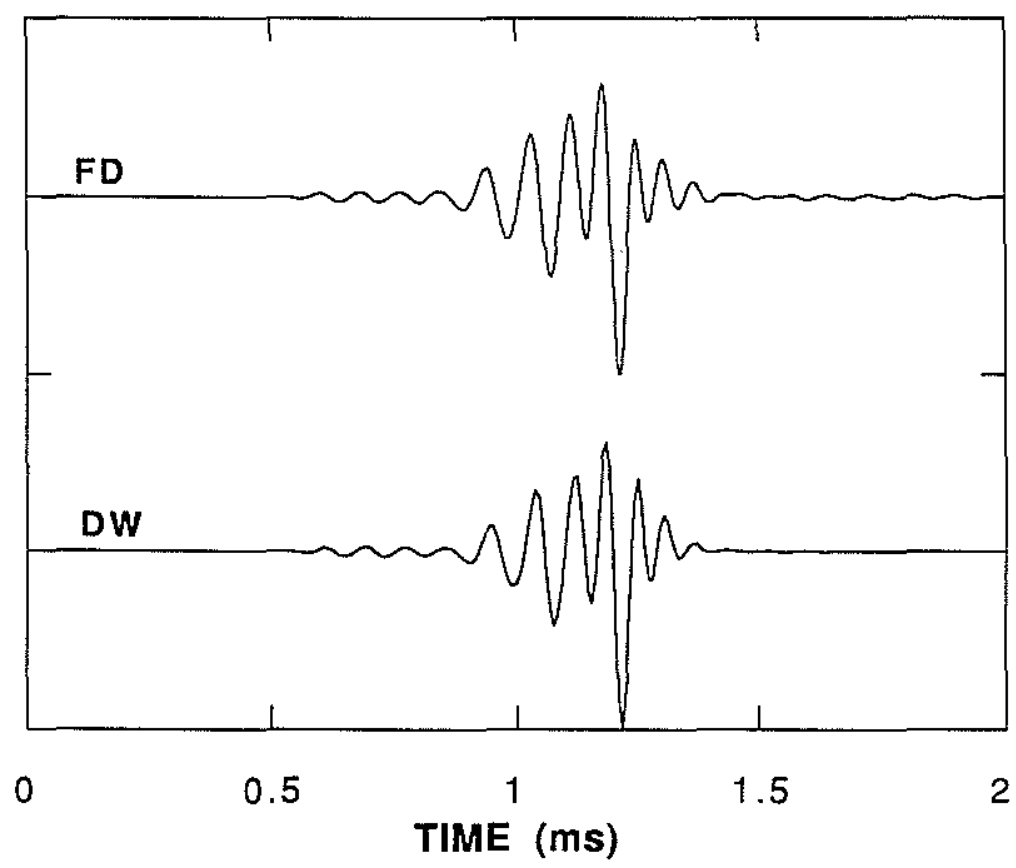

Figure 3: Comparison of finite difference (FD) synthetic waveform with discrete wavenumber method (DW). The separation of source-receiver is $2 \mathrm{~m}$. The center frequency of the source is $10 \mathrm{kHz}$. 


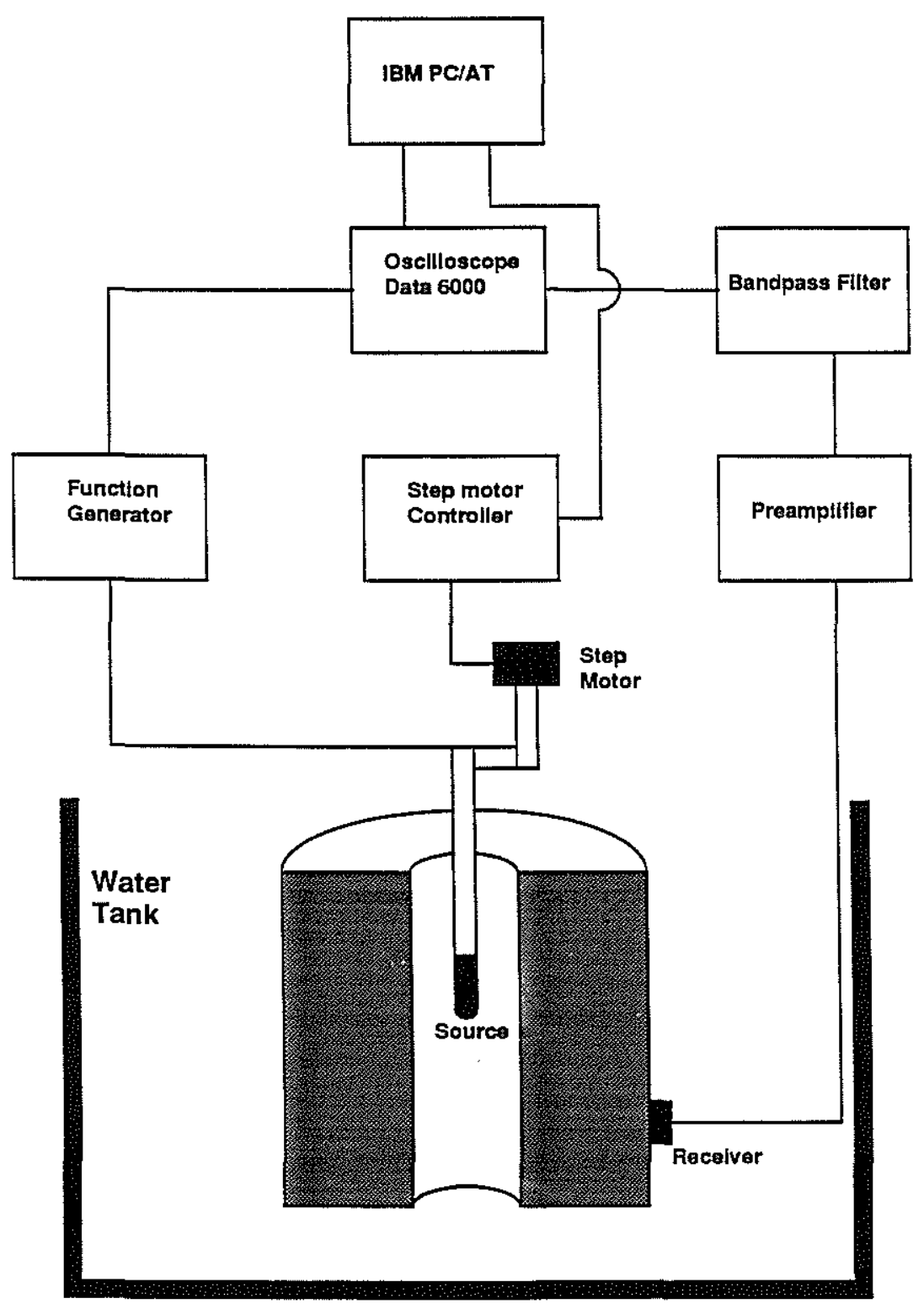

Figure 4: Block diagram of measuring system. 


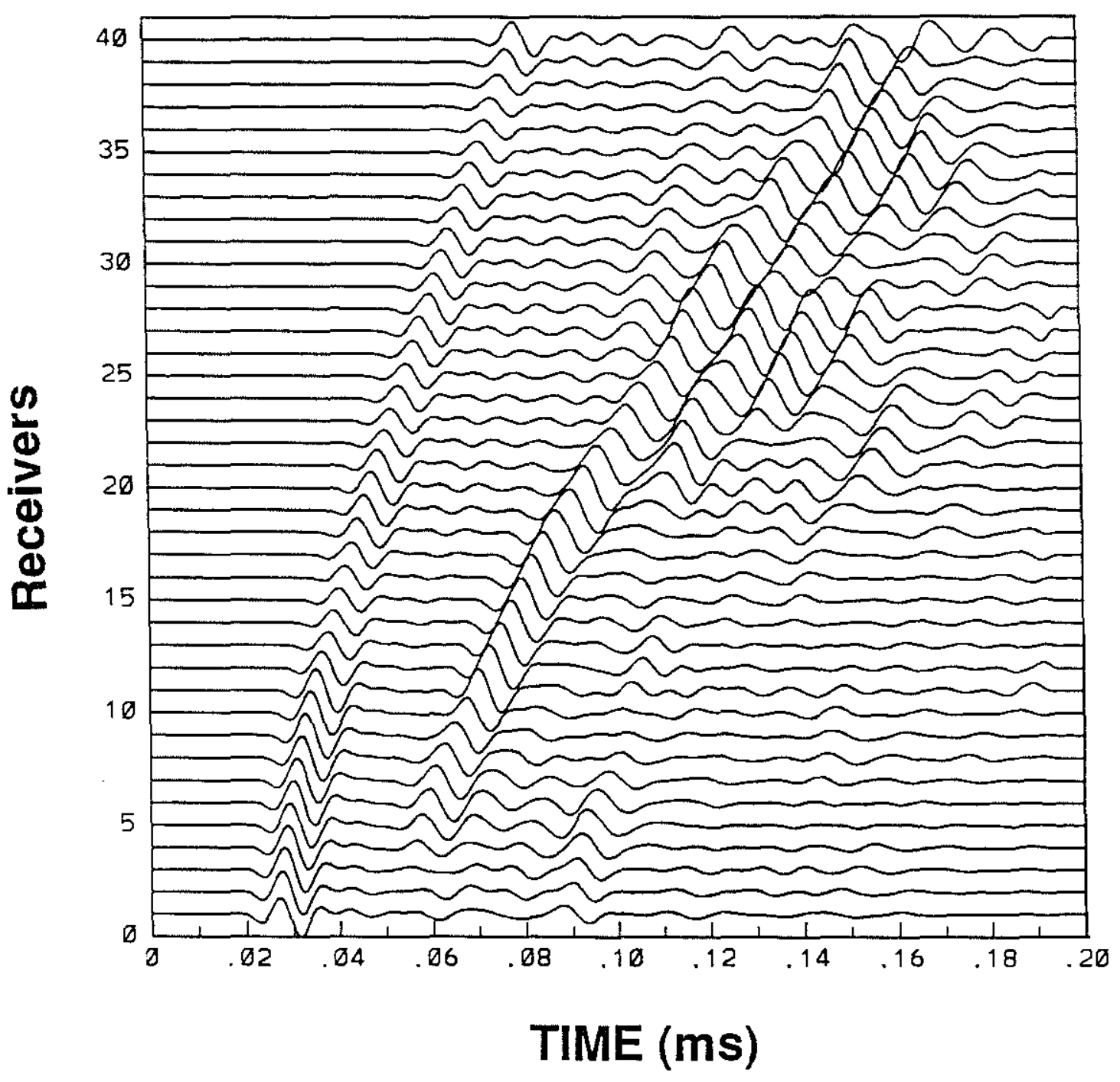

Figure 5: Waveforms measured outside of the lucite borehole model. The center frequency of the source is $100 \mathrm{kHz}$. The source moves up $0.5 \mathrm{~cm}$ after each measurement. 


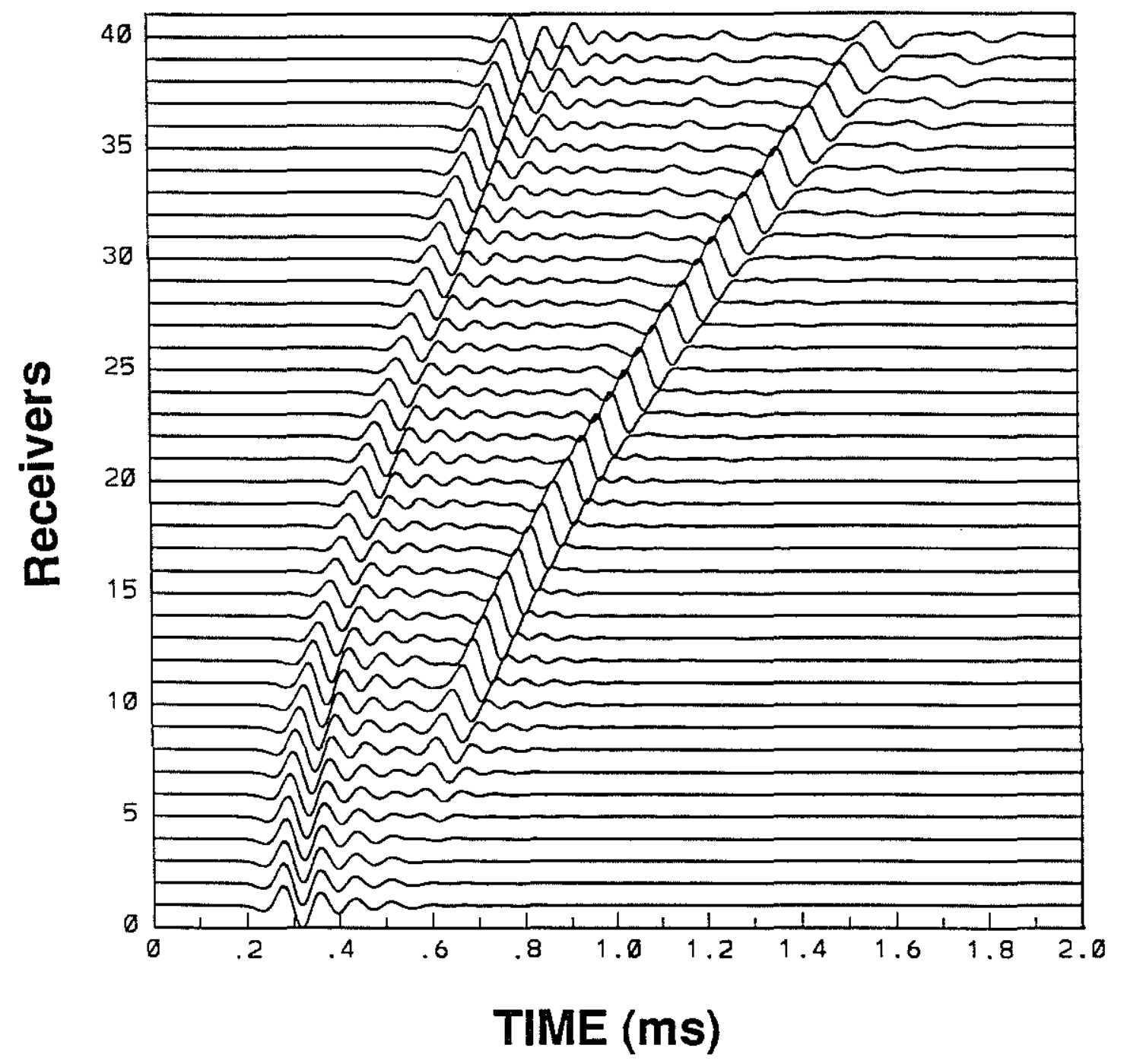

Figure 6: Finite difference synthetics of the lucite borehole model. Kelly source with 10 $\mathrm{kHz}$ center frequency is used. 


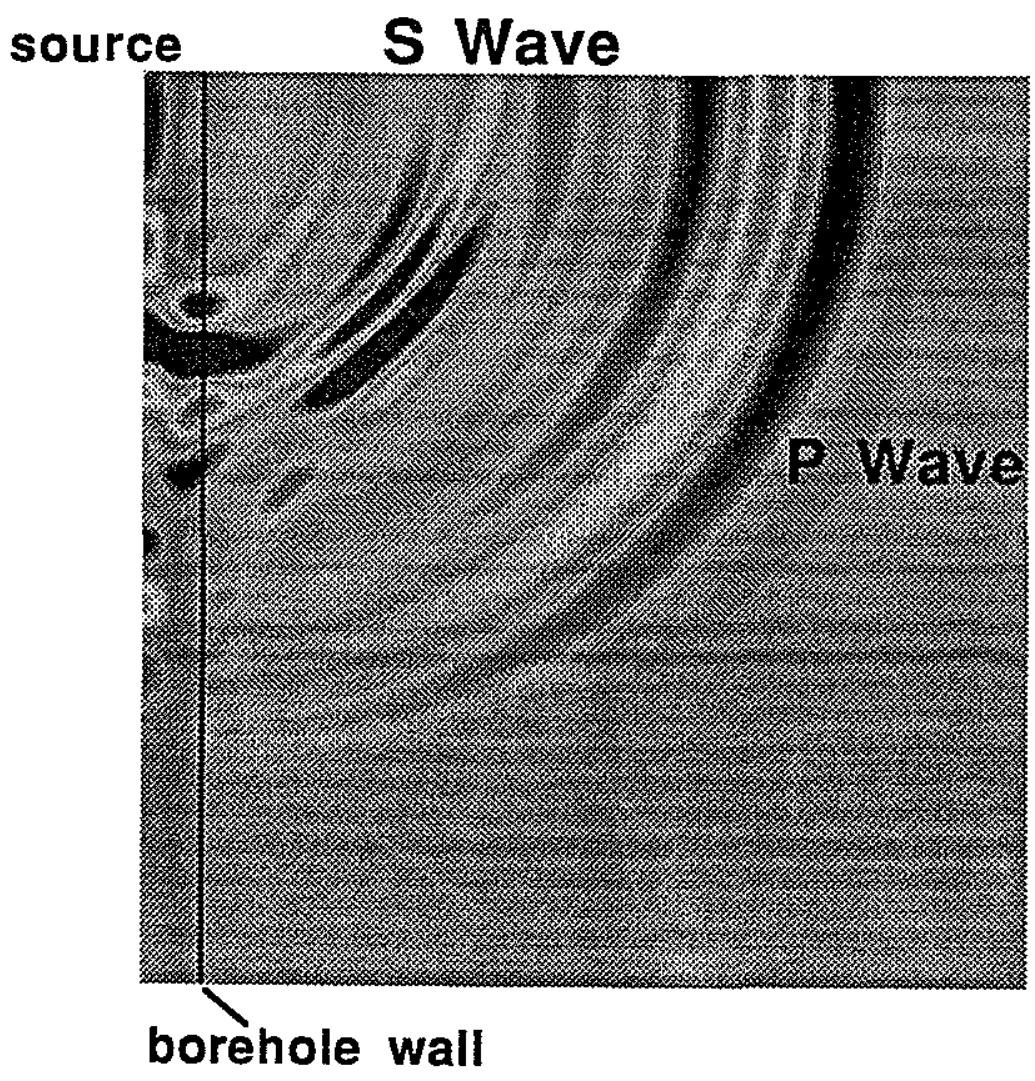

Figure 7: Snapshot of wavefield $\tau_{r r}$ for the lucite borehole model from finite difference simulation at time $0.5 \mathrm{~ms}$. 


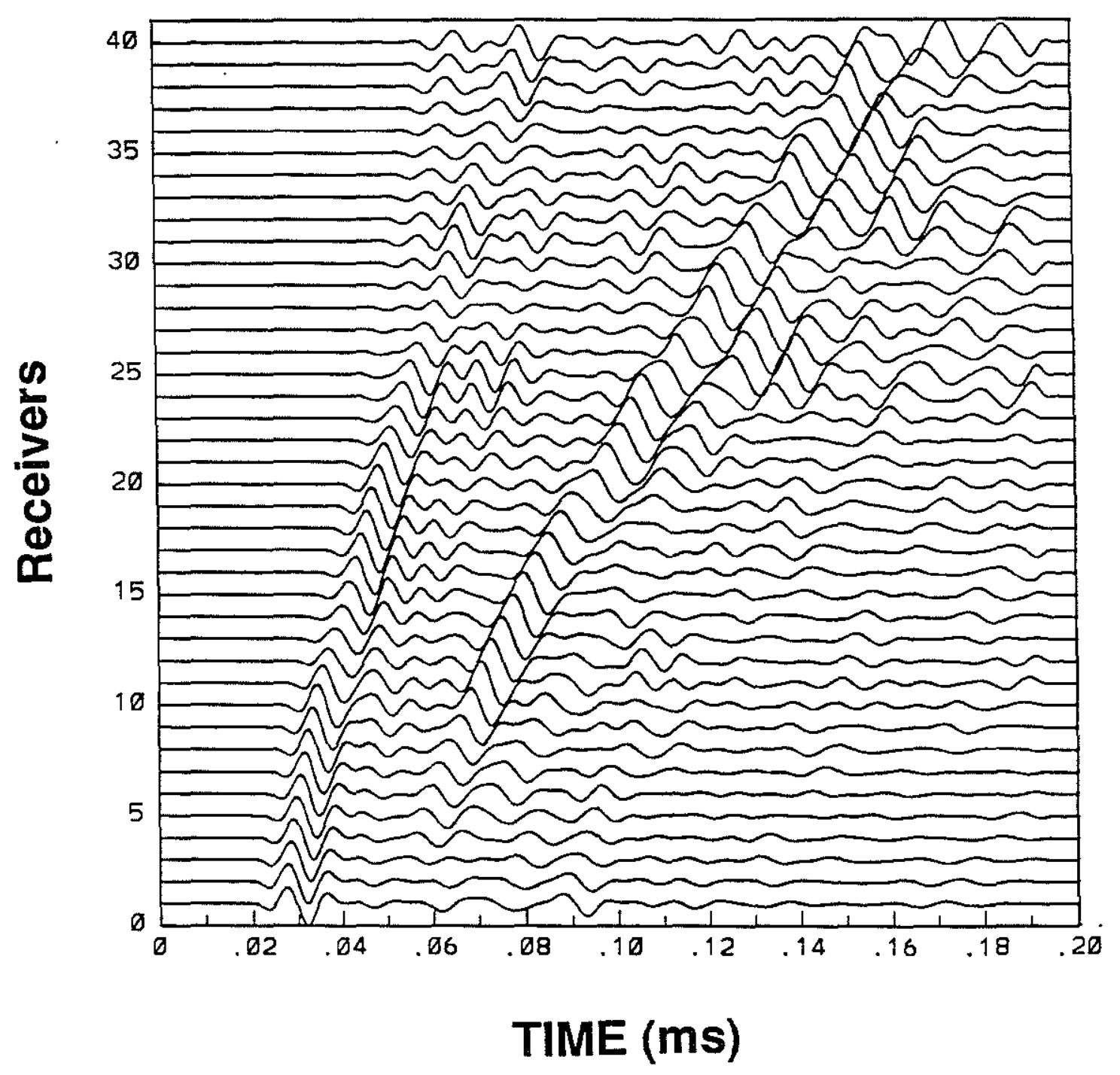

Figure 8: Waveforms measured outside of the lucite borehole model with a free glass pipe. The center frequency of the source is $100 \mathrm{kHz}$. The source moves up $0.5 \mathrm{~cm}$ after each measurement. 


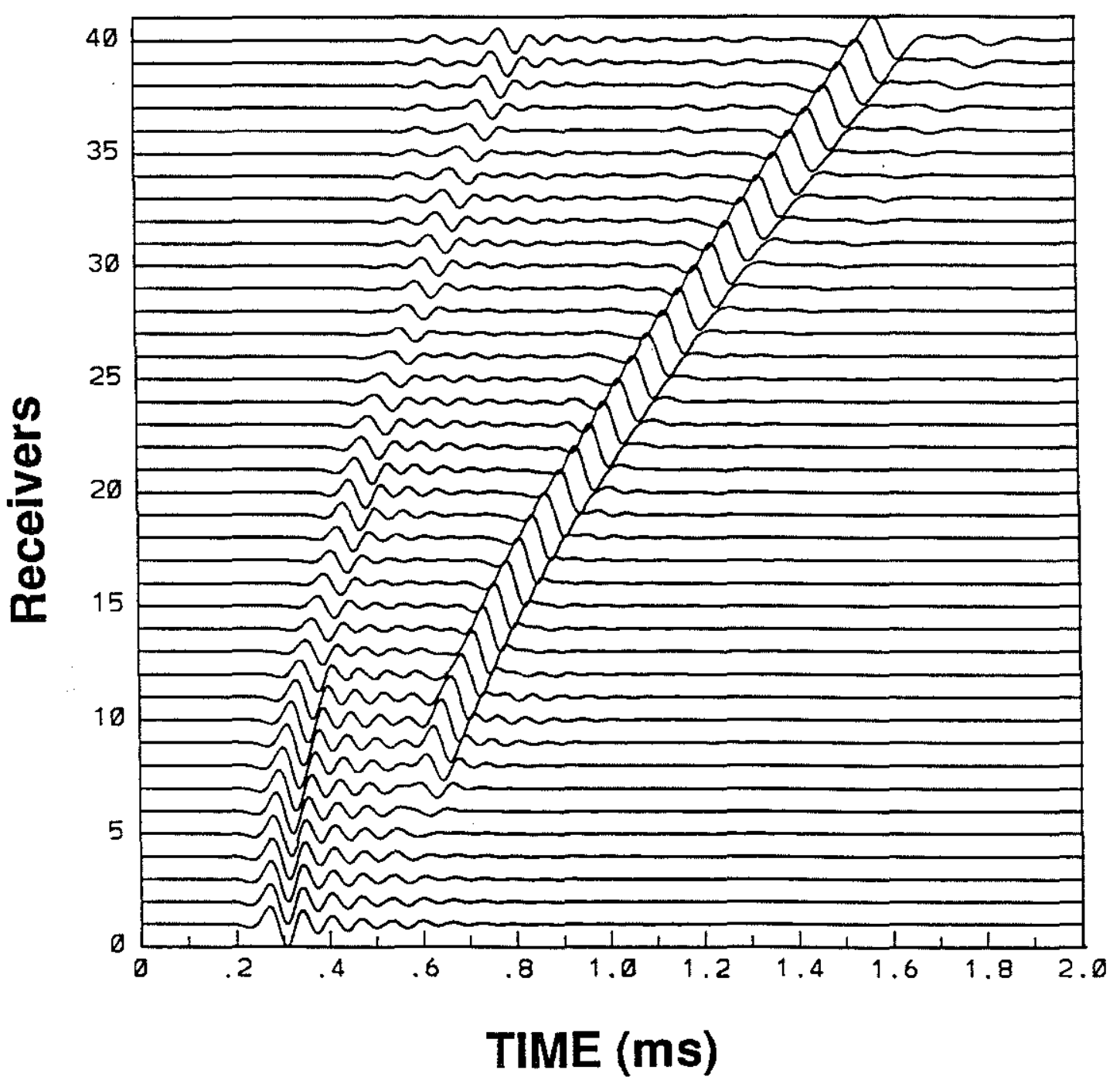

Figure 9: Finite difference synthetics of the lucite borehole model with a free glass pipe. Kelly source with $10 \mathrm{kHz}$ center frequency is used. 


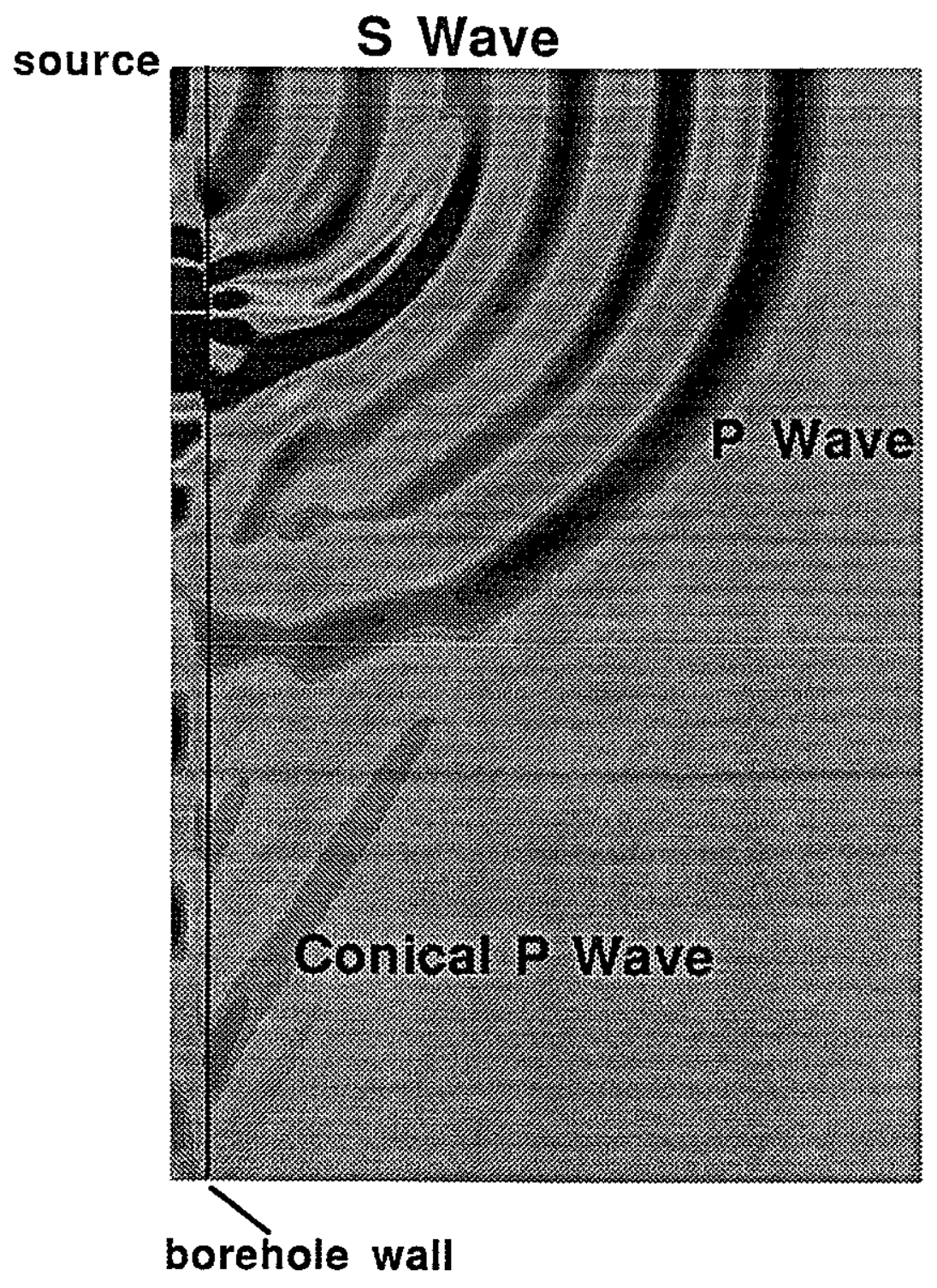

Figure 10: Snapshot of wavefield $\tau_{r r}$ for the lucite borehole model with a free glass pipe from finite difference simulation at time $0.5 \mathrm{~ms}$. 


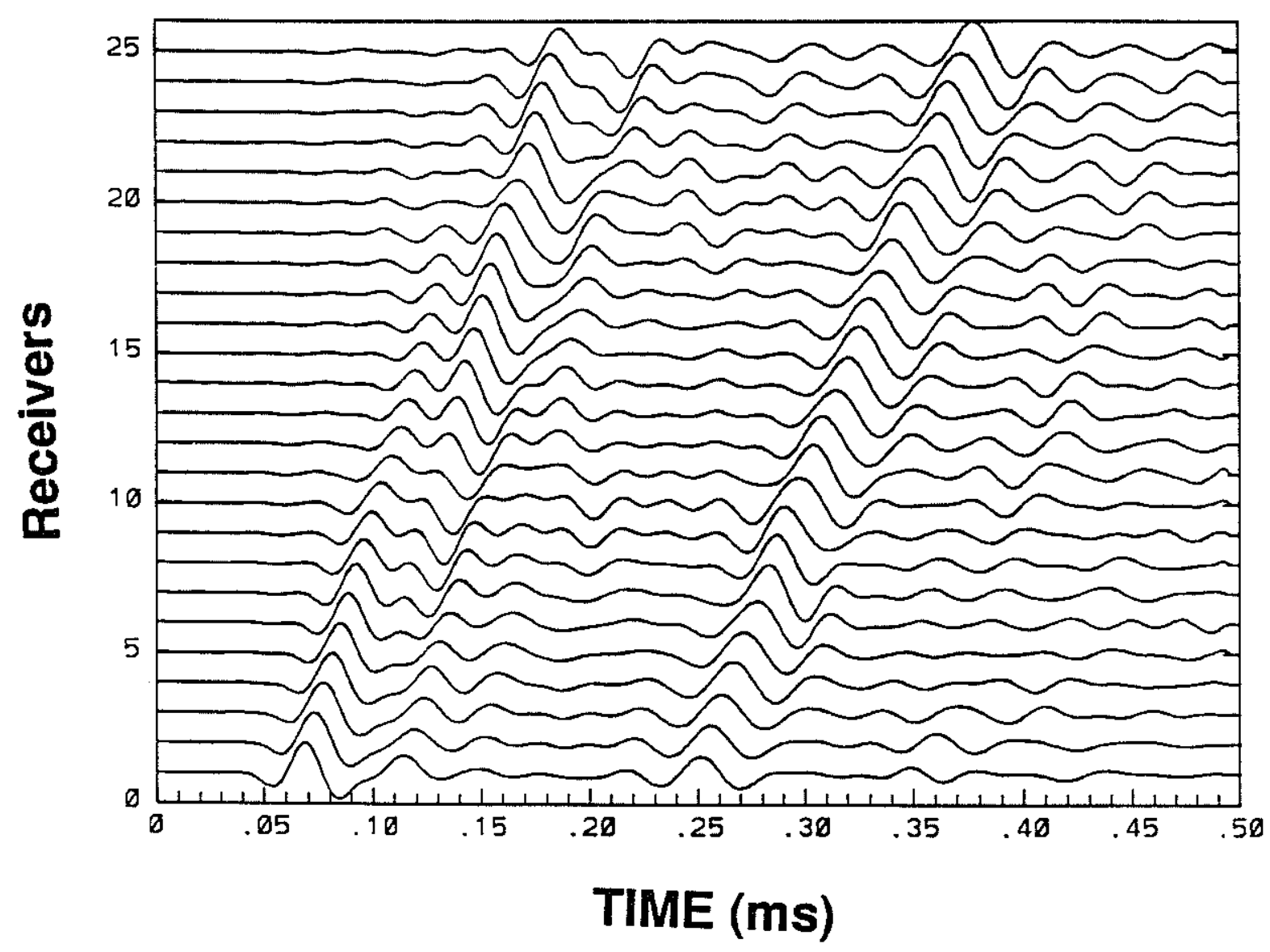

Figure 11: Waveforms measured outside of the glass cased soil borehole model. The center frequency of the source is $30 \mathrm{kHz}$. The source moves up $0.65 \mathrm{~cm}$ after each measurement. 


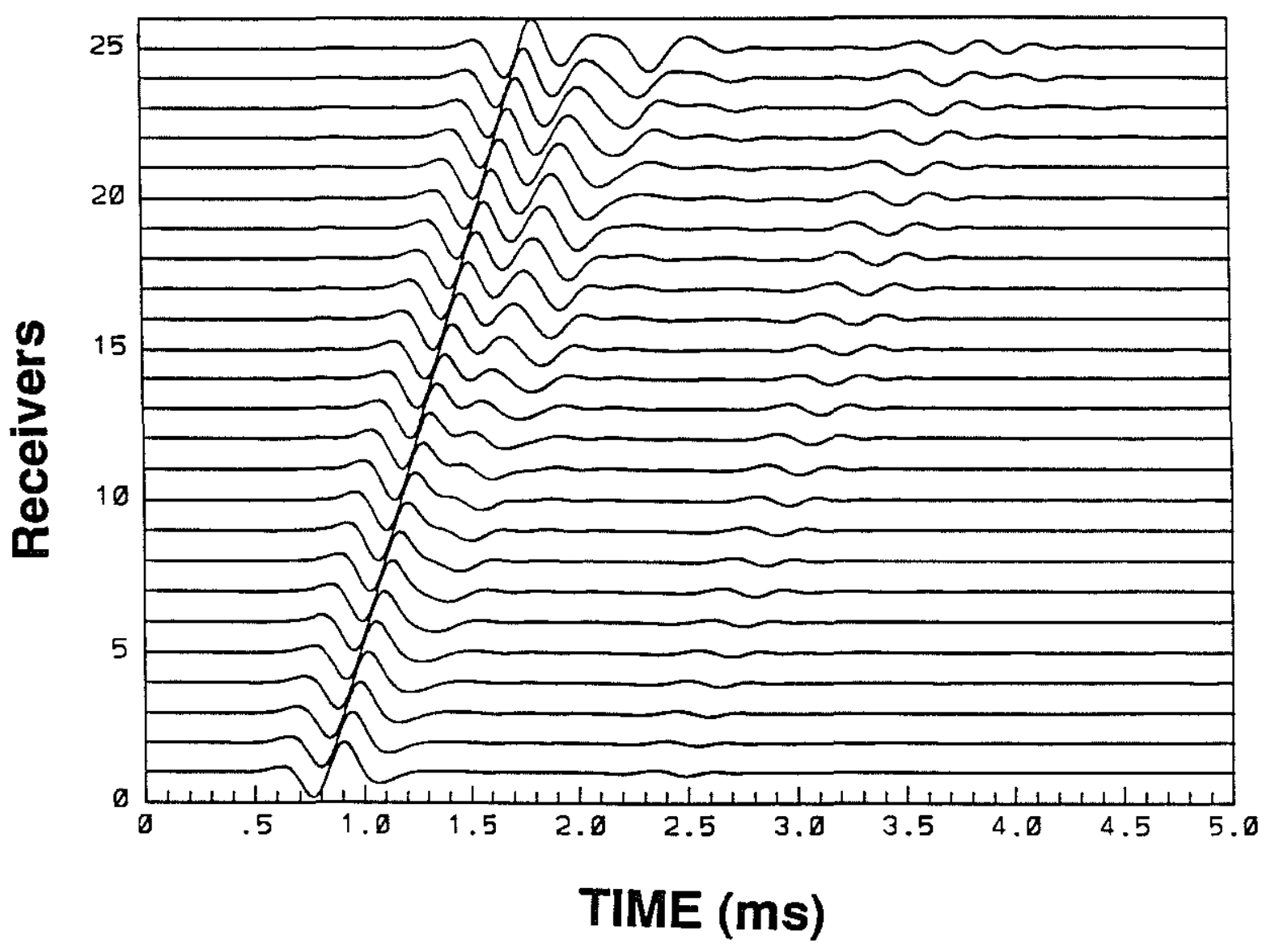

Figure 12: Finite difference synthetics of the glass cased borehole model. Kelly source with $3 \mathrm{kHz}$ center frequency is used. 


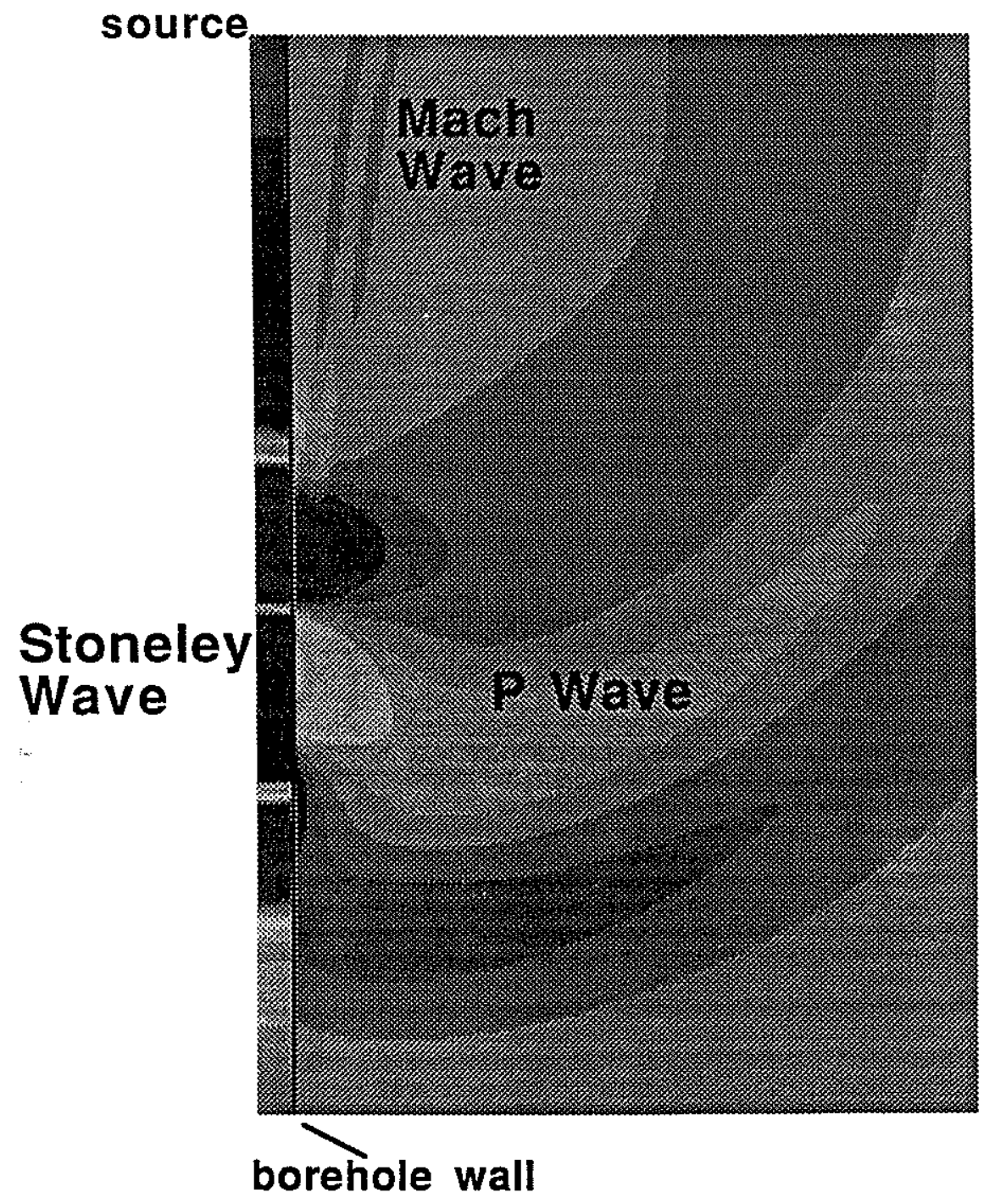

Figure 13: Snapshot of wavefield $\tau_{r r}$ for the glass cased soil borehole model from finite difference simulation at time $1.15 \mathrm{~ms}$. 


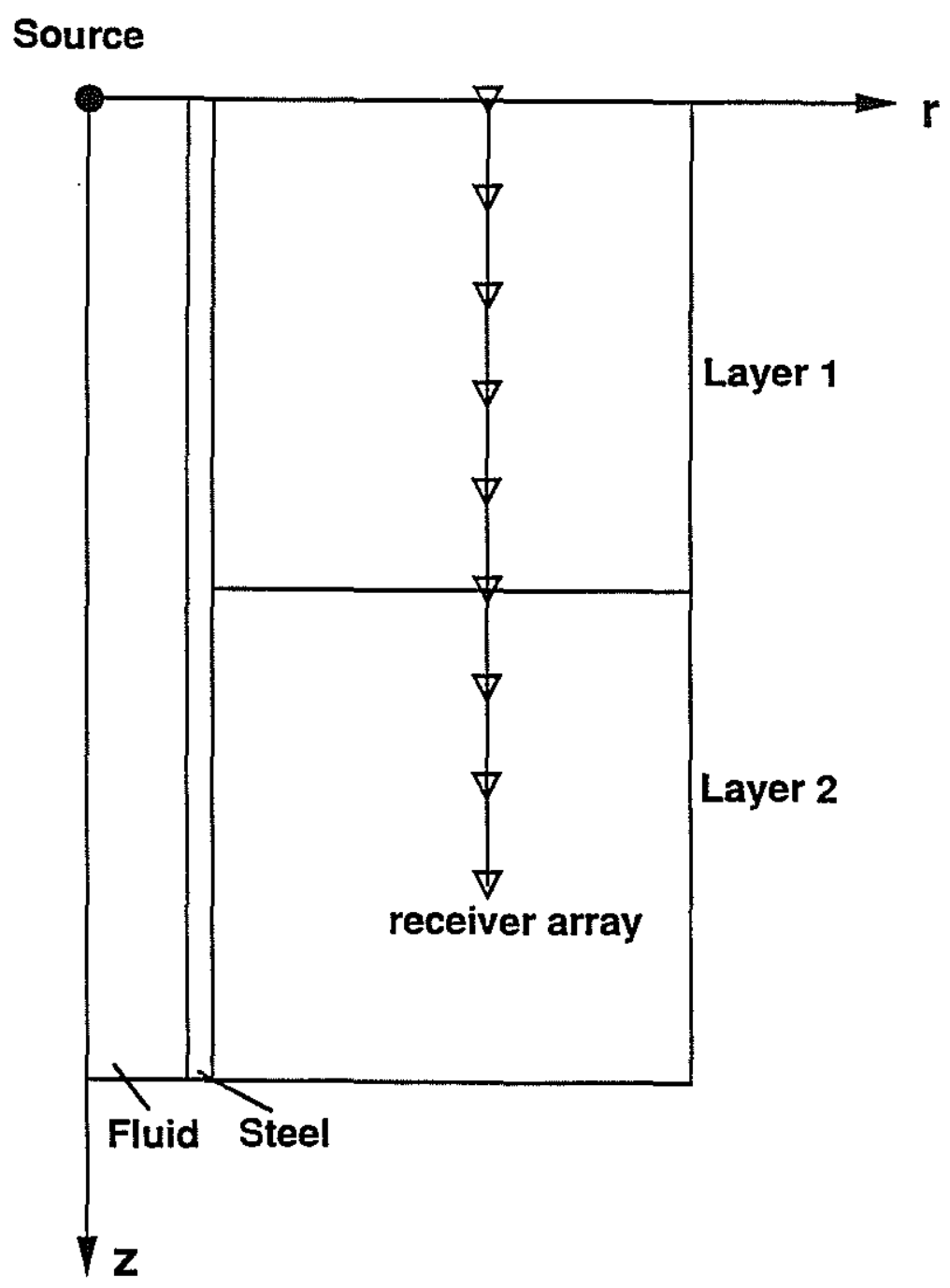

Figure 14: Borehole geometry used to investigate Mach wave propagation in the horizontal layered formation. The receiver array also shows in the plot. 


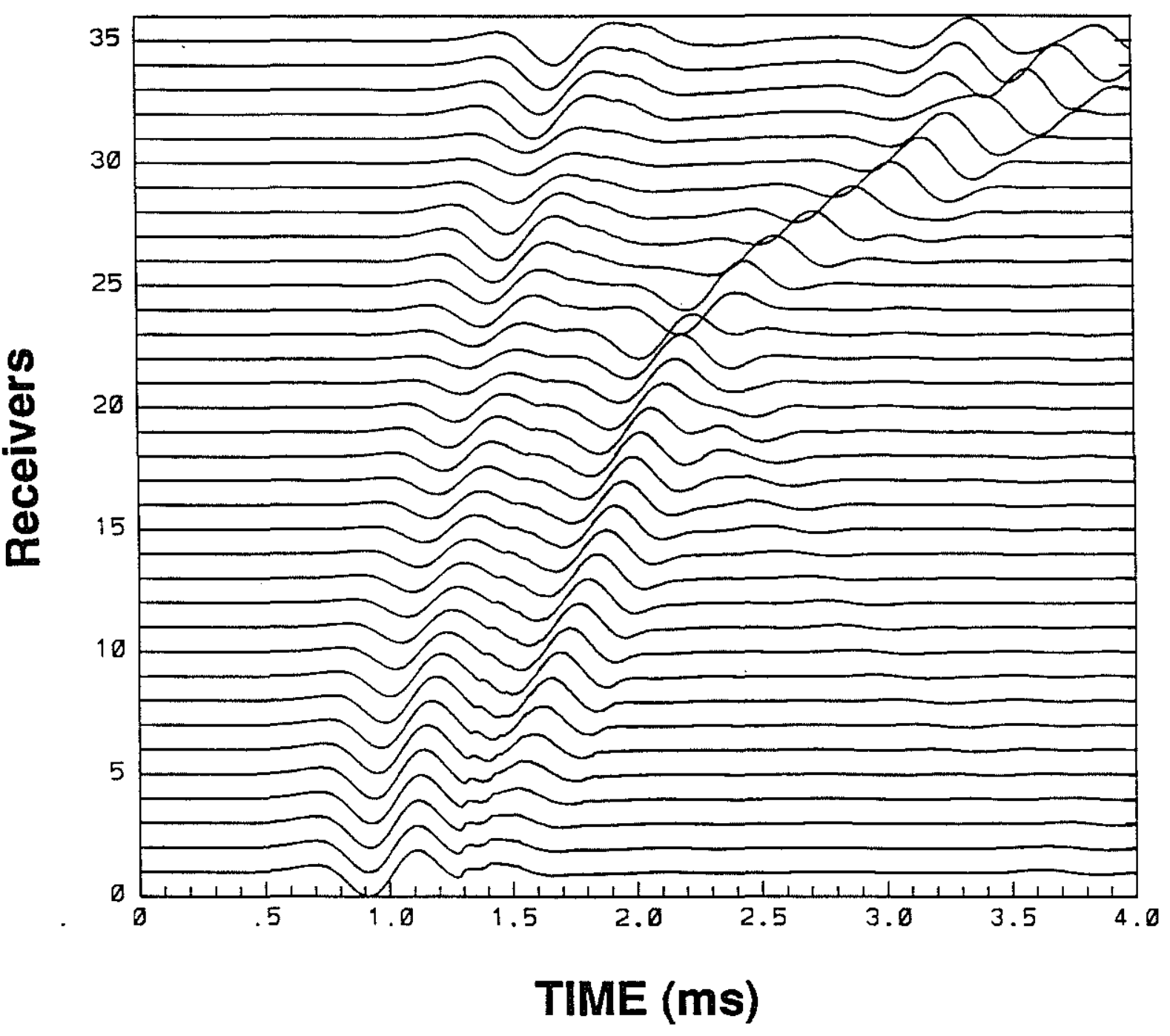

Figure 15: Waveform synthetics in the two slow layers formation. 


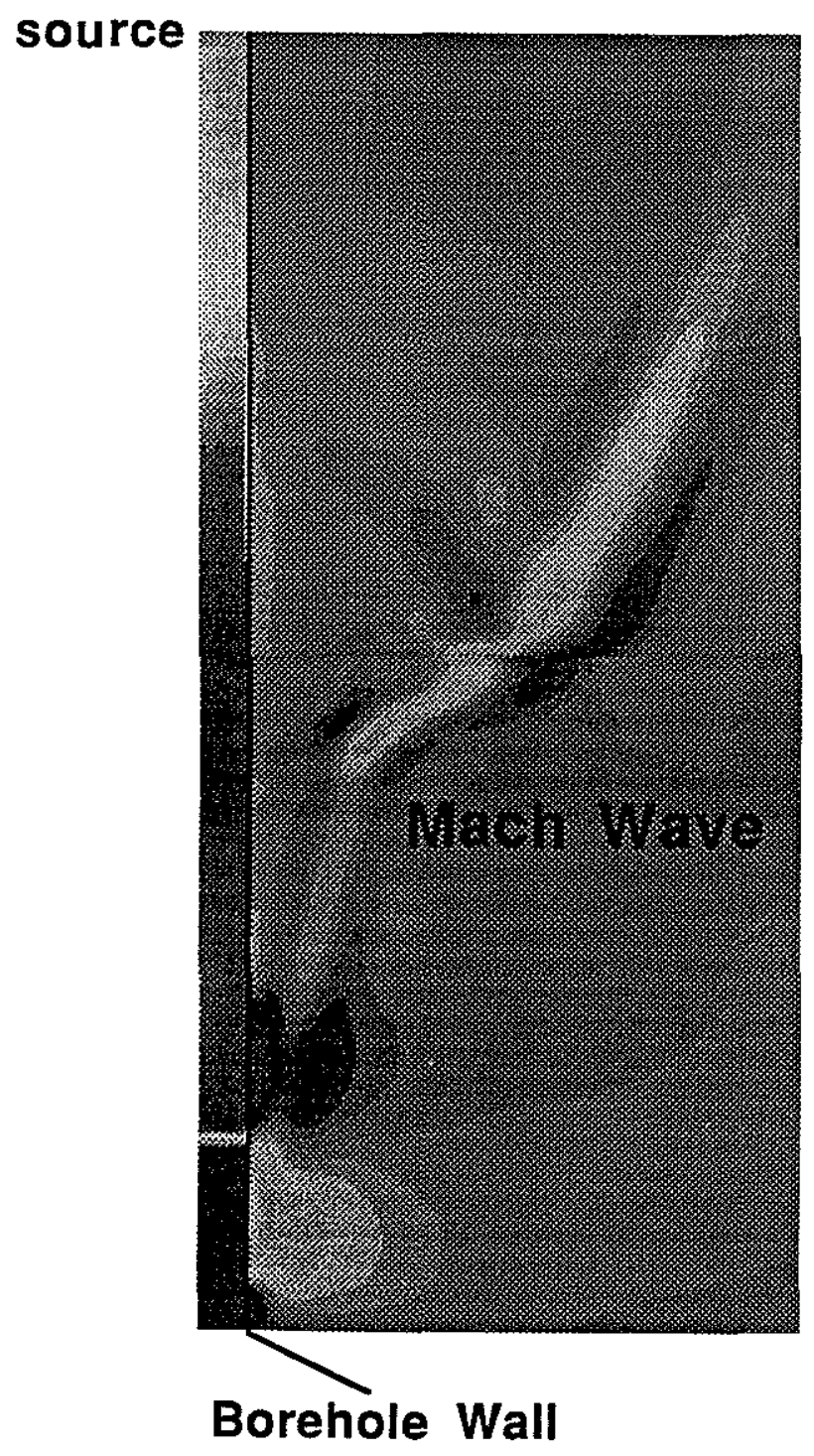

Figure 16: Snapshot of wavefield $\tau_{r r}$ in the two slow layers formation at time $2.4 \mathrm{~ms}$. 


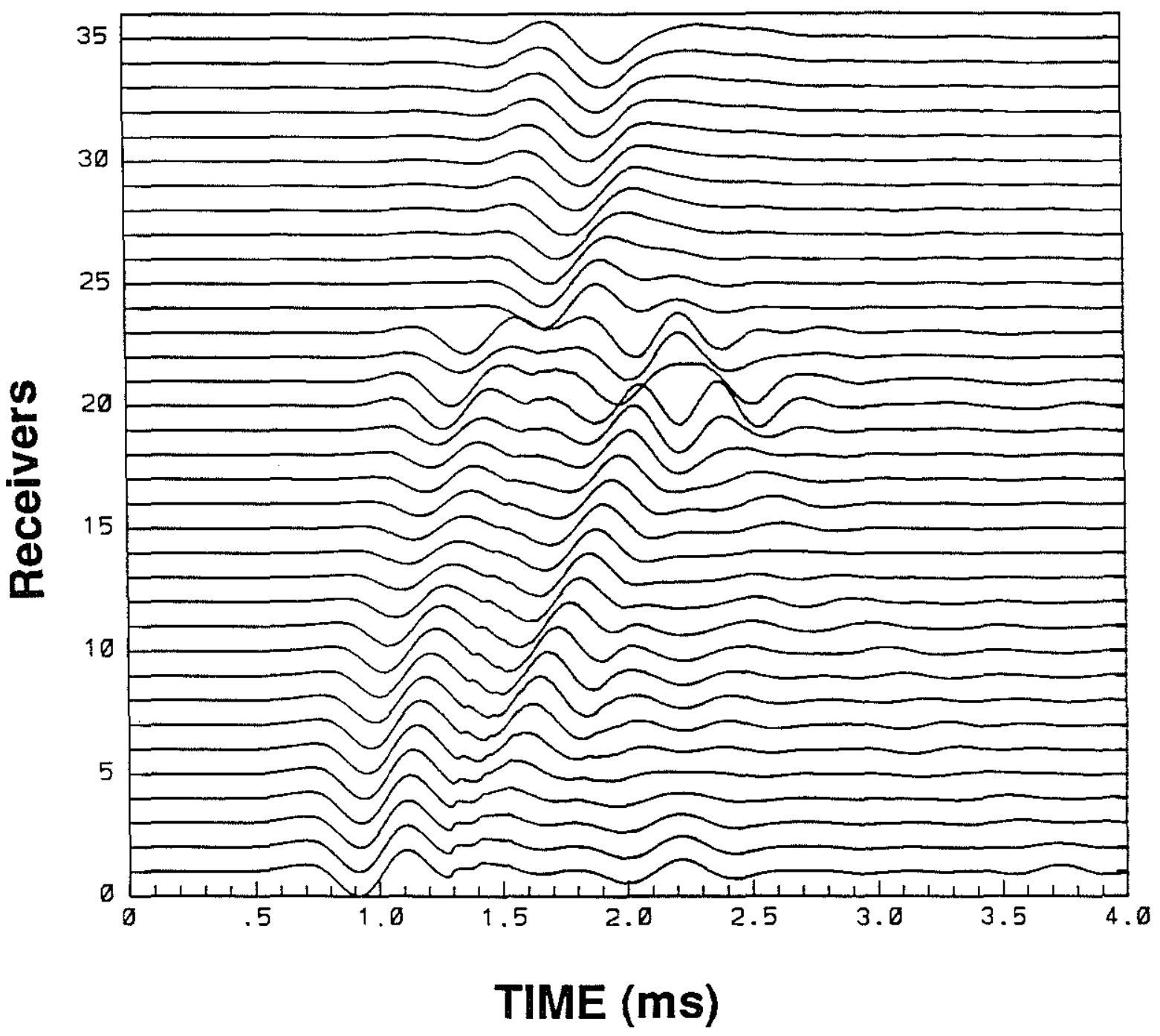

Figure 17: Waveform synthetics in the one slow and one fast layer formation. 


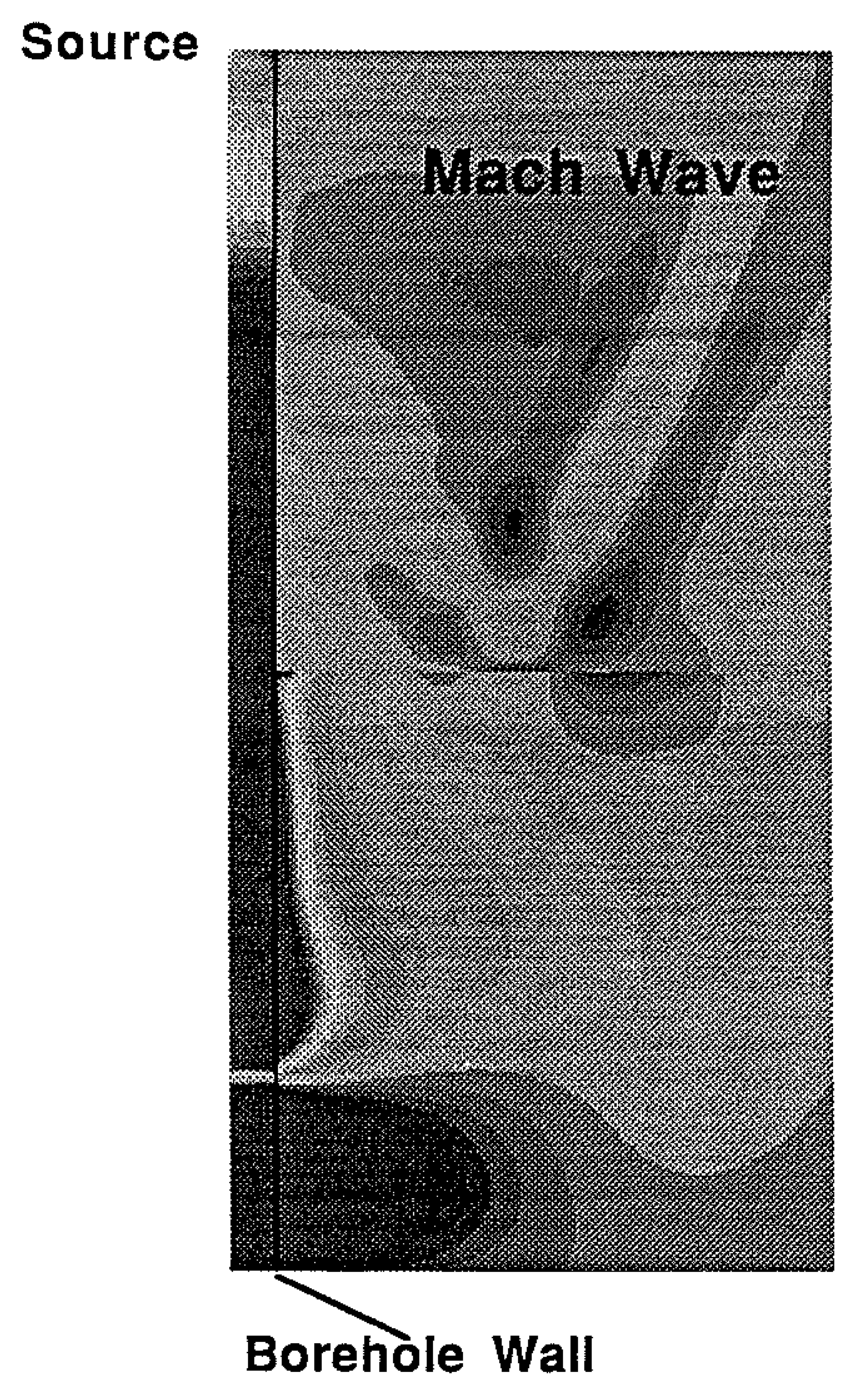

Figure 18: Snapshot of wavefield $\tau_{r r}$ in the one slow and the one fast formation at time $2.25 \mathrm{~ms}$. 